\title{
Colonialidad, feminismo y procesos de emancipación
}

\author{
Coloniality, feminism and emancipation processes
}

Sofia Roizarena ${ }^{1}$

\section{Resumen}

En el presente trabajo proponemos analizar algunas narrativas orientalistas gestadas al calor de los procesos coloniales experimentados por países africanos de mayoría musulmana durante el siglo XIX y de qué manera esos relatos racializados operan y se resignifican al interior de diversos movimientos emancipatorios actuales, como lo es el feminismo occidental-hegemónico. En esta dirección invitamos a pensar en feminismos en plural y a reconocer otras cartografías posibles de resistencia.

Palabras clave: feminismo, colonialidad, orientalismo, Islam

\section{Abstract}

In this paper we propose to analyze some orientalist narratives developed in the heat of the colonial processes experienced by Muslim-majority African countries during the XIX century and how these racialized narratives operate and are re-signified within various current emancipatory movements, such as western-hegemonic feminism. In this direction we invite to think of feminisms in plural and to recognize other possible cartographies of resistance.

Keywords: feminism, coloniality, orientalism, Islam

«Nuestras luchas actuales, como feministas africanas están directamente vinculadas a nuestro pasado como continente, a los contextos precoloniales, a la esclavitud, la colonización, las luchas de liberación, el neo colonialismo, la globalización.

Los Estados africanos modernos se construyeron a espaldas de las feministas africanas, que lucharon junto con los hombres para la liberación del continente» ${ }^{2}$

Recibido: 31 de marzo de 2021 Aceptado: 3 de junio de 2021 Publicado: 8 de julio de 2021

${ }^{1}$ Profesora de Historia. Egresada de la Facultad de Humanidades y Artes de la Universidad Nacional de Rosario (UNR), Rosario, Argentina. Correo electrónico: roizarenasofia@gmail.com ID https://orcid.org/00000002-2080-7448

${ }^{2}$ Carta de Principios Feministas para las Feministas Africanas. Noviembre, 2006, Ghana. 


\section{Introducción}

Los procesos de colonización emprendidos sobre territorios africanos desde principios del siglo XIX a cargo de Francia e Inglaterra, conllevaron la creación de una serie de discursos sobre la alteridad con un objetivo común: la construcción de un otro. Estos, calaron fuertemente en la estructura del pensamiento occidental. Dicho de otro modo, las prácticas discursivas lograron institucionalizarse de forma tal que una de sus principales expresiones fue la creación de la Escuela de Estudios Orientales y Africanos ${ }^{3}$ en 1916, con dependencia de la Universidad de Londres.

En relación a la cuestión orientalista es necesario establecer algunas salvedades. En primer lugar, el movimiento intelectual y académico que aquí evocamos, el cual halló sustento y legitimidad en un proceso mucho más amplio, el imperial, presentó a lo largo de diversas décadas contribuciones realizadas por distintas disciplinas de diferentes Estados. Sin embargo, tal como señala Edward Said (2008), el orientalismo que nos interesa es el que fue orquestado por Gran Bretaña y Francia y al que se sumó posteriormente Estados Unidos.

Se creó así un entramado de discursos coloniales que encontraron sustento ideológico, político y cultural en una sociedad receptiva a estas narrativas. En la medida en la que se reforzaba la construcción de un otro mediante mecanismos de fabricación específicos de lo ajeno, lo diferente y lo lejano, indirectamente se constituía la noción de un nosotros que enalteció la imagen europea a medida que profundizó la otredad africana. De este modo, el orientalismo es valioso en tanto “símbolo del poder europeo-atlántico ejercido sobre Oriente." (Said, 2008, p.20)

En este sentido, emerge de la estructura del pensamiento colonial la necesidad de esquematizar y ordenar la información de manera binaria. Así, binomios como modernidad - colonialidad, blanquitud - negritud, civilización - barbarie, científico religioso, comenzaron a inundar aquellos discursos que argumentaban un predominio europeo innato y necesario sobre un espacio que se construyó en base a relatos y retratos de una sociedad, que en términos darwinianos, se encontraba en estadios inferiores al desarrollo experimentado por occidente.

Mención aparte merece la dicotomía reforzada en estos relatos sobre orienteoccidente. En primer lugar, estas nociones deben ser comprendidas como una construcción histórica a partir de la cual ambos espacios se revelan de forma

\footnotetext{
${ }^{3}$ Uno de los principales exponentes de esta casa de estudios ha sido Bernard Lewis. Luego de haberse formado y ejercido como docente allí, se unió como miembro emérito de la cátedra de Estudios sobre Oriente Medio en la Universidad de Princeton en Nueva Jersey. En 1978 protagonizó un álgido debate con el teórico palestino, Edward Said, tras la publicación de "Orientalismo". En esta obra, Said denuncia la creación de estereotipos románticos y exóticos que dicha escuela forjó sobre los pueblos africanos y arabo islámicos.
} 
simultánea. De este modo, al surgir de manera contrapuesta, la definición de uno, indirectamente refleja la imagen de ese otro. La cuestión versa en que esta construcción teórica no solo delimitó dos grandes áreas geográficas, sino que a cada una de ellas se les adjudicó una serie de valoraciones que difícilmente pudieron ser al día de hoy descolonizadas.

De estas valoraciones y características subyace una relación de poder. Uno de los principales desafíos con los que nos encontramos es que el orientalismo entendido como "estilo occidental que pretende dominar, reestructurar y tener autoridad sobre Oriente" (Said, 2008, p.17) se erige ante la comunidad académica como un discurso verídico de conocimiento sobre esta vasta región, prácticamente como una especialidad a la que cualquier cientista social puede aplicar.

Siguiendo esta misma línea, es necesario destacar, tal como lo propone la obra de Said, la diferencia entre conocer con el propósito de coexistir y el conocer para dominar y controlar un área geográfica y a su población. De algunos de los saberes que esta doctrina estimó evidenciar, se desprenden una serie de elementos que merecen ser desagregados.

Por un lado, parte de los mecanismos que se emplearon para argumentar la alteridad oriental, consistieron en reducir la innumerable cantidad de lenguas, pueblos, tradiciones y experiencias bajo un mismo rótulo. De esta manera el proceso de orientalización del otro consistió en desconocer las especificidades propias de cada región, de cada grupo poblacional y por ende convertir a este continente en un amplio espacio homogéneo. Incluso en la actualidad se desprende como parte de la lucha que se libre contra estos preceptos, consignas que vociferan "África no es un país”.

Por el otro, la cosmovisión de estas sociedades africanas, sus instituciones y sus modos de organización fueron sometidos y analizados bajo las estructuras del pensamiento occidental. Desde esta perspectiva se juzgó particularmente la presencia de la religión en ámbitos que exceden lo privado. Así, la falta de secularización de estas comunidades se convirtió en el elemento condenatorio y en símbolo de un "atraso" claramente distinguible. Esto fue reforzado aún más por algunos teóricos estadounidenses quienes asumieron que la modernidad sólo podía ser comprendida dentro de su laicidad. Por lo tanto, estamos en presencia de un proceso histórico que se caracterizó por ser excluyente y ajeno, al menos, a dos tercios de la población mundial.

Asimismo, deviene de los análisis orientalistas un tercer elemento que establece prácticamente una falta de mérito para la autodeterminación de los pueblos africanos. Dicho de otro modo, estas sociedades difícilmente puedan alcanzar un nivel de organización y control de su población basado en los ideales democráticos y 
republicanos heredados de una tradición antigua anclada en la experiencia griega o romana, o en el legado de, por ejemplo, la Revolución Francesa. En palabras de Said, Ha sido tan abrumador y calculadamente agresivo el ataque contra las sociedades contemporáneas árabes y musulmanas, acusándolas de ser retrógradas, carecer de democracia y abrogar los derechos de las mujeres, que se nos olvida que las nociones de modernidad, iluminismo y democracia no son conceptos acordados por todos. (Said, 2008, p.23)

Podemos aventurar que estas trayectorias de modernidad auto instituida, imprimieron en la "civilización europea" una tarea evangélica. Europa se convirtió en un faro, el cual buscaba iluminar las experiencias oscurantistas que atravesaban otras regiones, admitiendo el desarrollo histórico europeo como un desarrollo unidireccional y de alcance universal. De este modo, occidente hizo parte de sí la tarea de socorrer y "europeizar" al otro. Una adjudicación de la que, aún en la actualidad, seguimos encontrando rastros. Sin embargo, previo a esta etapa de europeización, fue necesario profundizar la otredad que suponía oriente. En tal sentido, los argumentos orientalistas oscilaban entre las siguientes declaraciones,

En un principio, la respuesta musulmana a la civilización occidental fue de admiración y emulación: un respeto inmenso por los logros de Occidente y un deseo de imitarlos y adoptarlos. Sin embargo, en nuestra época esta actitud de admiración y emulación se ha convertido, para muchos musulmanes, en una de hostilidad y rechazo. En parte, esta actitud se debe seguramente a un sentimiento de humillación: la conciencia creciente, entre los herederos de una civilización antigua, orgullosa y durante mucho tiempo dominante, de que aquellos a quienes consideraban inferiores los han atajado, sometido y arrollado. (Lewis, 2001, p. 7)

Desde esta perspectiva, era inviable pensar una salida oriental a los desafíos políticos y culturales que la realidad exige. Incluso, yendo un poco más lejos, ha sido frecuente en el discurso colonial asumir que muchos de los "males" que atravesaba la sociedad europea, como lo es el sistema patriarcal, en los pueblos africanos en general y en las sociedades musulmanas en particular, dicho escenario se profundiza aún más, alcanzando niveles de complejidad más peligrosos que los desplegados en Europa. De esta manera, Bernard Lewis sostendrá que,

Las acusaciones son de sobra conocidas. A nosotros los occidentales se nos acusa de sexismo, racismo e imperialismo, institucionalizados en el patriarcado y la esclavitud, la tiranía y la explotación. Ante estas acusaciones, y otras igualmente infames, no nos queda otra opción que declararnos culpables: no en tanto estadounidenses $u$ occidentales, sino 
simplemente como seres humanos, como miembros de la raza humana. En la comisión de estos pecados no somos los únicos pecadores y, en algunos de ellos, no somos ni de lejos los peores. El trato a las mujeres en el mundo occidental, y más generalmente en la cristiandad, siempre ha sido desigual y a menudo opresivo, pero incluso en sus peores momentos fue mejor que el régimen de poligamia y concubinato que ha sido la suerte casi universal de las mujeres en este planeta. (Lewis, 2001, p. 7)

Y sobre este último apartado merecen ser atendidas algunas cuestiones. En primer lugar, la percepción de que los males occidentales adquieren un mayor vicio en sociedades como las comunidades arabo islámicas es una idea muy extendida incluso en el presente. Más allá de que el colonialismo imperial encontró su ocaso tras la II Guerra Mundial, aún nos enfrentamos a la tarea de desandar sus vastas estructuras. Para ello, es necesario tener presente que,

La colonialidad trasciende la historia; es el aparato de poder que se gesta en el periodo colonial y se refiere a la forma en que el trabajo, el conocimiento la autoridad y las relaciones intersubjetivas se articulan entre si, a través del mercado capitalista mundial, la idea de raza y el sistema de sexo-género. (Adlbi Sibai, 2017, p. 27)

De esta manera, los procesos independentistas que atravesaron los Estados Africanos representan el fin de una etapa de sujeción hacia sus metrópolis, pero el desafío actual radica en descolonizar aquellas estructuras de poder y saber, gestadas durante dicho escenario y que aún dominan parte de las narrativas que infieren una subvaloración sobre las realidades de estos pueblos. Por lo tanto, el proceso de descolonización implica desandar los conocimientos producidos desde finales del siglo XIX y la primera mitad del siglo XX sobre estas comunidades, y en nuestro caso particular, nos interesa deconstruir la imagen producida y reproducida de las mujeres islámicas.

\section{Una mirada colonial del Islam y sus mujeres}

Desde la administración colonial que se institucionaliza en el orientalismo y tiene como principal referente a Bernard Lewis, el islam fue concebido como una religión primitiva la cual somete a sus creyentes. Su caracterización, minada de connotaciones negativas, se debate en un legado aberrante que fluctua entre la incitación a la poligamia y el destrato y confinamiento que padecen sus mujeres. En tal sentido, y retomando las ideas previas, si la mujer occidental se ve sometida por el orden patriarcal, se infiere que la mujer musulmana lo está al menos en tres niveles. Uno determinado por su condición colonial, el otro fundado en la religión que profesa 
y finalmente una dominación en el plano doméstico, primero sumida a su padre, luego a su esposo.

Algunas de estas lecturas gestadas al calor de la política colonial, sobre todo aquellas que retrataban la realidad de las mujeres musulmanas, en la actualidad siguen haciendo mella en el sentido común occidental. Parte de este mérito está determinado por el tratamiento que estos discursos han tenido en los medios masivos de comunicación. Incluso, algunos de ellos calaron tan hondo en la sociedad que, empezar a desnaturalizar ciertas prácticas, hoy en día conlleva necesariamente a interpelar un sinfín de relatos producidos aún por movimientos emancipatorios, como lo es el feminismo.

Feminismo e islam se presentan en nuestro sentido común como una cuestión dicotómica, prácticamente como un desafío que dificilmente pueda lograr una sintesis que incluya a ambos términos. En primer lugar, cabe destacar que no nos es ajena la realidad del movimiento, sus diversas maneras de organización, sus formas de lucha y los contenidos que le dan sustento. Sin embargo, existe un claro perfilamiento de una de las vertientes del feminismo, un feminismo "occidental", el cual se erige frente a la problemática, como hegemónico. Es decir, más allá de las especificidades propias de cada región, población y cultura, reconoce una única salida a la situación, y es la experiencia europea.

$\mathrm{Al}$ igual que otros procesos que experimentó Europa, el feminismo occidental se instituye como un movimiento de carácter y alcance universal. Por fuera de éste, quedan otros feminismos que no se circunscriben a un marco teórico estrictamente europeo o estadounidense, sino que están delimitados por experiencias regionales y culturales que representan una salida en materia de género para aquellas sociedades que no se encuentran atravesadas por las mismas prácticas que llevamos adelante de este lado del hemisferio.

De esta manera, si analizamos parte de las declaraciones que dan sustento a estos discursos, notamos como en el feminismo están presentes nociones coloniales que asumen que los pueblos tercermundistas, mediante la ayuda de los países desarrollados e industrializados, podrían alcanzar niveles de vida y sistemas políticos y económicos similares a los de estos. El desarrollo se convierte así en un proceso lineal que dibuja la trayectoria de un pueblo que avanza desde la condición de subdesarrollado (atrasado, tradicional y primitivo) hacia el plenamente desarrollado: moderno, progresista, racional e industrializado. (Adlbi Sibai, 2017, p. 44)

A partir de la década de 1970 la agenda política mundial junto a la de organismos no gubernamentales y de derechos humanos, avizoran tópicos como "Mujer y Desarrollo.” Estas temáticas eclosionan sobre el último cuarto del siglo XX, a la par de 
un surgimiento sin precedentes en el campo académico e intelectual del feminismo occidental. Es en este contexto en el que se esbozan preocupaciones que giran en torno a ¿cómo lograr el desarrollo de la mujer tercermundista? ¿Cómo alcanzar la emancipación de las estructuras tradicionales en las que se halla inmersa?

Cabe señalar que, estas preocupaciones no hacen más que reforzar el ideal orientalista que describe a la mujer arabo-islámica como un sujeto pasivo, sin voz propia. Estas prenociones han inundado el sentido común de la sociedad y ha quedado manifiesto que la única forma de virar ese destino, es de la mano de occidente. Por lo tanto, se anula cualquier posibilidad de concebir a la mujer musulmana como una compañera en el proceso de lucha y pasa a ser un sujeto que aguarda por su liberación. Así la construcción de otredad se resignifica ahora en 'nosotras', las feministas, y 'ellas', las oprimidas.

Pero, ¿de qué hay que liberarlas? Por lo general, las principales denuncias que buscan evidenciar la situación que atraviesa la mujer musulmana, sumida en una cultura patriarcal sacralizada por la religión, insisten en la prohibición del uso del niqab, hijab, burka o velo ${ }^{4}$. Este debate si bien ha colmado varios portales en la actualidad, es una situación presente desde el mismísimo período colonial.

Siguiendo a Frantz Fanon, en su obra sobre Argelia, realiza un planteo en el que deja de manifiesto que desde la administración colonial se combatió vigorosamente el uso del velo, ya que consideraban que detrás de ese sistema patriarcal claramente visible, se esconde un matriarcado doméstico. Por lo tanto, lograr que la mujer se 'convierta', se occidentalice, implica necesariamente haber conquistado un poder real sobre el hombre argelino y por lo tanto sobre su cultura. Para fortalecer este planteo, Fanon (2002) sostendrá que,

La administración dominante se propone defender solemnemente a la mujer humillada, eliminada, enclaustrada. Se describen las posibilidades inmensas de la mujer, desgraciadamente transformada por el hombre argelino en un objeto inerte, devaluado y hasta deshumanizado. El comportamiento del argelino es denunciado enérgicamente y comparado con las costumbres medievales y bárbaras. (p. 18)

Por lo tanto, si bien estos métodos adquieren nuevos interlocutores, los mismos siguen manteniéndose vigentes hace más de medio siglo. Y en este caso particular, el feminismo occidental en tanto movimiento emancipatorio que se pretende universal, logra ser excluyente y redefine, dentro de sus narrativas, prácticas coloniales.

Como demostramos, la controversia que se origina sobre el uso del niqab, en tanto prenda de vestir que representa simbólicamente niveles sumamente complejos de

\footnotetext{
${ }^{4}$ En el discurso feminista occidental estos conceptos se utilizan como sinónimos, lo cual evidencia el desconocimiento que hay sobre la cultura de una sociedad que se pretende liberar.
} 
patriarcado y machismo, no es una preocupación exclusivamente de los tiempos que corren. Sin embargo, en la actualidad el debate oscila entre la obligatoriedad del uso del niqab por parte de los estados musulmanes y la prohibición de esta prenda de vestir en sociedades occidentales con fuerte presencia musulmana, como lo son España y Francia. Ninguna de las salidas contempla el uso voluntario del mismo, por lo tanto, sea desde una perspectiva o la otra, ambas desoyen la decisión de las mujeres que resuelven llevarlo (o no).

Incluso en palabras de Brigitte Vasallo, miembro de la Red Musulmana de Feminismo Islámico, sostiene que,

pensar que el burka es patriarcal y que las mujeres no tienen manera de redomarlo es una mirada colonial. El debate debería estar en torno a si es legítimo obligar o prohibir a una mujer a vestirse de una manera determinada y si realmente nuestras prohibiciones $\mathrm{u}$ obligaciones no atentan contra el derecho al propio cuerpo y la propia imagen. ${ }^{5}$

Ahora bien, resulta interesantísimo analizar cómo desde los feminismos arabo islámicos, la discusión está por encima del uso del burka y del debate mediático del cual ha sido objeto en los principales portales ${ }^{6}$. La atención de movimientos como Feminismo Islámico, Unión Feminista Egipcia, Federación de Mujeres Musulmanas Asociadas en Nigeria, entre otros tantos, está centrada en la relectura y reinterpretación de los textos sagrados como el Corán y la Sunnah, ya que más allá de tratarse de fuentes primarias y de vital importancia en el Islam, no solo rigen la vida religiosa sino que regulan aspectos concernientes a lo cultural, político y social. En la comprensión occidental del Islam, el limite entre lo público y lo privado se encuentra difuminado.

Cabe destacar, que un concepto sustancial para este análisis es el de Sharia el cual ha sido ampliamente extendido como el de Ley Islámica. Lo fundamental, radica en entender que este representa un marco jurídico y legal que compatibiliza los saberes descritos en el Corán y la Sunnah con la realidad política y gubernamental de cada Estado. Por lo tanto, los grupos feministas islámicos entienden que lograr un viraje en el rumbo de sus destinos implica, en primera instancia, volver a las fuentes y

\footnotetext{
5 Recuperado de https://arainfo.org/brigitte-vasallo-pensar-que-el-burka-es-patriarcal-y-que-las-mujeresno-tienen-manera-de-redomarlo-es-una-mirada-colonial/

${ }^{6}$ Esta cuestión ha sido abordada sobre todo por los periódicos pertenecientes a países europeos en los que reside población musulmana. Podemos destacar 'El País' y ‘El Mundo’ de España, Le Monde en Francia. Sugerimos algunos articulos que plantean el debate: https://www.lemonde.fr/le-monde-desreligions/article/2020/11/29/le-port-du-voile-integral-n-est-pas-determine-par-la-religion-mais-par-lerapport-aux-hommes_6061521_6038514.html https://www.lemonde.fr/les-decodeurs/article/2015/06/11/niqab-hijab-burqa-des-voiles-et-beaucoup-deconfusions_4651970_4355770.html https://elpais.com/internacional/2017/07/14/actualidad/1500039190_647533.html
} 
alcanzar una reinterpretación que sea más amena con el género, ya que consideran que muchas de las prácticas patriarcales que pueden denunciarse están ancladas de manera estructural a la tradición de estos países, pero no así al Islam per se.

Es preciso señalar que los movimientos feministas arabo-islámicos, sobre todo aquellos de larga data, como lo es la Unión Feminista Egipcia - fundada en 1923 - o la Unión Musulmana de Mujeres de Túnez -creada en 1956-, al igual que sucede en occidente, se han visto resignificados a lo largo del tiempo, atravesando diferentes etapas, de acuerdo a las demandas que el contexto amerita. Siguiendo a Paradela Alonso (2014), en primer lugar abogaron por una mayor representatividad en el espacio público, el derecho al trabajo fuera del ámbito doméstico y finalmente la necesidad imperiosa de re-comprender las escrituras para conseguir legitimar su rol frente a un Estado y a una sociedad, que en mayor o menor medida, y no por ello distinto a la realidad occidental, las oprime.

Por consiguiente, estas organizaciones van más allá del uso del niqab. Intentan, desde su propia idiosincrasia, generar un cambio cualitativo en las estructuras sociales que asegure y logre perpetuar una realidad más justa para mujeres y disidencias, sin que estas entren en conflicto con la religión y la cultura que profesan. La puesta máxima está en la educación como modo de autonomización.

Ahora bien, estas agrupaciones no sólo tienen que hacer frente y buscar una salida al sistema patriarcal que las somete y sujeta, sino que también se enfrentan al desafío de re legitimarse frente a quienes podrían considerarse compañeras de lucha (aunque esto no suceda por las reticencias y resistencias del movimiento occidental) "nosotras".

De esta manera, y en sintonía con lo que se conoce como pinkwashing instaurado por Jasbir Puar (2017), surge lo que Brigitte Vasallo ha denominado el purplewashing. En palabras de ella,

el purplewashing no enmascara la islamofobia, sino que la legítima, la justifica. Construye un binomio antagónico entre derechos, en este caso, de las personas musulmanas, y derechos de las mujeres y que sitúa a las mujeres musulmanas en un limbo de invisibilidad que forma parte de la violencia sistemática y las excluye de las reivindicaciones hegemónicas de los derechos de las mujeres, que pasan a hacerse a su costa. Desde la perspectiva del purplewashing, las mujeres musulmanas, en tanto que musulmanas, no son mujeres ${ }^{7}$

Por lo tanto, este tiene el propósito de visibilizar cómo desde los mecanismos de implementación de luchas feministas subyacen políticas de exclusión sobre aquellas

\footnotetext{
7 Recuperado de https://www.elconfidencial.com/cultura/2016-04-03/del-pornoburka-al-purplewashinglos-trucos-mas-sucios-contra-el-feminismo_1170764/
} 
sociedades minorizadas. Asimismo, el movimiento acusa la existencia de una instrumentalización de discursos feministas coloniales con una fuerte presencia de elementos racistas y xenófobos.

\section{Consideraciones finales}

Los mecanismos de racialización que entran en juego en las narrativas coloniales son múltiples. Encontramos algunas tipologías que tras jerarquizarse y naturalizarse devienen en estereotipos que no hacen más que producir y reproducir la diferencia. Sin duda alguna, el principal rasgo que adquieren estos procesos racializantes que se despliegan en la medida en la que se co-inventa al africano, están basados en la pigmentación. Como anticipamos, el binomio blanquitud-negritud acapara la escena. De la mano del 'color' -soporte material de una categoría- se crea un sinfín de sub valoraciones sobre ese grupo.

Sin embargo, con el correr del tiempo estos mecanismos empiezan a pendular entre la visibilidad y la invisibilidad. Si bien como ejemplo paradigmático podemos citar al pueblo judio, la comunidad musulmana es también racializada por variables que no hallamos en la superficie. Las acometidas contra este sector por la religión que profesan y la cultura que practican han sido brevemente comentadas en las páginas anteriores, sobre todo en relación a las mujeres que integran la $u m m a^{8}$.

Cabe destacar, que las valoraciones que se realizan sobre estos Estados en muchas oportunidades están sujetas a las acciones individuales de un grupo reducido de religiosos, sobre todo a lo que comúnmente se ha popularizado como fundamentalismo islámico. Siguiendo a Hall (2010), estos procesos van más allá de la producción misma de estereotipos, sino que convierten al individuo en la expresión de un grupo.

De allí se desprenden una serie de 'saberes' generalizados que se perciben sobre la mujer musulmana. Nuevamente la tan extendida caracterización de una mujer pasiva, sin capacidad de organización y movilización con sus pares, sometida a un sistema patriarcal que se estima mucho más profundo y estructural que el instalado en occidente, oprimida por su religión, su cultura y en el ámbito doméstico por los masculinos que la tutelan. Estas prenociones inundan hoy en día las narrativas que dan sustento al feminismo europeo y estadounidense.

Existe una gran contemplación de los movimientos arabo-islámicos concedida por el feminismo latinoamericano y viceversa. Estimamos que esto es posible ya que

\footnotetext{
${ }^{8}$ Por lo general el concepto suele traducirse como nación, sin embargo tal categorización termina minimizando los matices de la gramática árabe. Según la RAE se denomina como tal a la comunidad de creyentes del Islam. Lo fundamental, es que esta comunidad trasciende los límites geopolíticos y administrativos de cada Estado y reúne bajo sí a personas de diversos orígenes y ascendencias. Refiere a una comunidad sin fronteras.
} 
desde una perspectiva periférica, los procesos de colonización y descolonización atravesados por los estados africanos, más allá de las especificidades propias que adoptó cada región, han sido trayectorias que también emprendieron los pueblos latinoamericanos. Por lo tanto, pensar un feminismo decolonial es una tarea que está en la agenda de ambas luchas.

Lo fundamental es comprender que partir de conocimientos gestados al calor de la etapa colonial para entender la realidad de un amplio grupo de mujeres nos habilita una imagen sumamente parcializada. Que desde el feminismo occidental se interprete como una conquista digna de mención la prohibición del uso del hijab y todas sus variantes, no representará un cambio cualitativo en la calidad de vida de estos sujetos. Incluso aventuramos a aseverar que estaríamos en presencia de un proceso de desarraigo cultural más que un elemento emancipatorio. Plantear el uso voluntario del mismo, nos presenta otro panorama.

Sin embargo, como hemos visto, los movimientos feministas musulmanes se hallan inmersos en un debate que no responde a las urgencias occidentales, sino que sinérgicamente buscan una salida coherente a la problemática, la cual garantice soluciones concretas y perdurables a su situación.

De esta manera, intentamos exponer algunas narrativas que surgen en los albores mismos de los procesos coloniales que atravesaron los Estados africanos. Amén de los movimientos independentistas que lograron romper los lazos de sujeción con sus metrópolis, estos relatos siguen permeando nuestras percepciones y la imagen que seguimos recreando de ese "otro". La realidad nos interpela y resulta urgente realizar una autocrítica desde el feminismo occidental la cual ayude a incorporar una perspectiva decolonial, o al menos contemple el derecho a la organización y autodeterminación de otros sujetos no europeizados.

\section{Referencias bibliográficas}

Adlbi Sibai, S. (2017). La cárcel del feminismo: hacia un pensamiento islámico decolonial. Akal - Inter Pares.

Ali, Z. (2014). Feminismos islámicos. Tabula Rasa, № 21, pp. 123-137.

Bayona Mojena, R y Silverio González, Y. (2011). Feminismo musulmán y revueltas en el Medio Oriente: el papel de las mujeres islámicas. En Simposio Internacional Medio Oriente y Norte de África: Estados alterados y la geopolitica de la transformación, Buenos Aires.

Caggiano, S. (2015) Imaginarios racializados y clasificación social: retos para el análisis cultural (y pistas para evitar una deriva decolonial esencialista). Cuadernos Intercambio sobre Centroamérica y el Cáribe, Vol XII, $\mathrm{N}^{\circ} 2$, pp. 121-152. 
Fanon, F. (2012). Sociología de una revolución. Tolemia.

Hall, S. (2010). Sin garantías: trayectorias y problemáticas en estudios culturales. Corporación Editora Nacional.

Jabardo, M. (2012). Feminismos negros: una antología. Traficante de Sueños.

Lenore, V. (03/04/2016). Feminismo: del pornoburka al purplewashing: los trucos más sucios contra el feminismo. Recuperado de: https://www.elconfidencial.com/cultura/2016-04-03/del-pornoburka-alpurplewashing-los-trucos-mas-sucios-contra-el-feminismo_1170764/

Lewis, B. (2001). Las raíces de la rabia musulmana. Letras Libres, Año III, N³5.

Mahmood, S. y Hirschkind, C. (2004) Feminismo, fundamentalismo islámico y la política de la contrainsurgencia. Iconos, Revista de Ciencias Sociales, №20, Flacso.

Mir Hosseini, Z. (2011). Islam y feminismos: la apertura de un nuevo diálogo. Boletín Ecos, $\mathrm{N}^{\circ} 14$.

Ngozi Adichie, C. (2018). Todos deberíamos ser feministas. Literatura Random House. Paradela Alonso, N. (2014). El feminismo árabe y su lucha por los derechos de la mujer. Encuentros multidisciplinarios, $\mathrm{N}^{\circ} 46$.

Puar, J. (2017). Ensamblajes terroristas. El homonacionalismo en tiempos queer. Ediciones Bellaterra.

Quijano, A. (2014). Colonialidad del poder y clasificación social. Cuestiones y 161 Horizontes, CLACSO.

Said, E. (2008). Orientalismo. De Bolsillo.

Segato, R. (2013). La crítica de la colonialidad en ocho ensayos y una antropología por demanda. Prometeo Libros.

Solana, A. (8/12/2014). Brigitte Vasallo: Pensar que el burka es patriarcal y que las mujeres no tienen manera de redomarlo es una mirada colonial. Recuperado de https://arainfo.org/brigitte-vasallo-pensar-que-el-burka-es-patriarcal-y-quelas-mujeres-no-tienen-manera-de-redomarlo-es-una-mirada-colonial/

Zirion Landaluze, L. (2014). Los feminismos africanos. Las mujeres africanas "en sus propios términos”. Relaciones Internacionales, № 27, UAM. 